\title{
Operational results and future trends of filtration technology in minerals processing
}

\author{
J Palmer Outotec Pty Ltd, Australia
}

\begin{abstract}
Water in mining is the commodity that has driven the mining industry for decades. Often used frivolously, modern economic and social pressures are forcing change to use less water and to improve the quality of water and effluents. Used in many processes, water is ultimately consumed in tailings disposal and technologies which can increase the recovery of water are constantly being developed.

Filtration and thickening are often seen as competing technologies for water recovery however new cases are developing that show significant advantages can be achieved by combining the two technologies to develop the most effective solution.

Supported by case studies this paper investigates the merits of each of the technologies and which strategies of combining the two produce the best outcomes.

\section{$1 \quad$ Water in mining}

Mineral processing applications generally require water for the processing of ores, whether utilising physical or chemical methods. Water is first added in the milling stage and additional water added as required throughout the circuit. Water losses from the circuit are principally associated with the tailings stream. Optimised water recovery is necessary both because it is a scarce commodity and to minimise the environmental impact.
\end{abstract}

Water recovery is usually accomplished through a sedimentation or filtration processes. Water can be removed from the tailings impoundment by evaporation but this does not improve the mine's water consumption. The water recovery methodology also determines the water quality; increasing water recovery concentrates solutes in the process water and may create recirculating loads of fine solids.

\subsection{Sedimentation}

Sedimentation is a process where a slurry or solid-liquid mixture is separated into dense slurry containing most of the solids and an overflow of essentially clear water (or liquor in leaching processes). The driving force for the separation is the gravitational field where the differences in phase densities define the rate of separation of the phases. In mining applications sedimentation is applied to both the product and tailings streams to recover water which is recycled in the process.

The degree of separation achievable with sedimentation is affected by the particle size, shape, surface chemistry and solids density. These variables are evident in thickeners as the rise rate which describes the area required to recover the design supernatant flow and the compression depth which determines the degree of further dewatering in the bed.

By adding flocculants and increasing the depth of thickeners, higher degrees of separation can be achieved. At low concentrations solid-liquid mixtures behave like a liquid (described primarily by a viscosity) and at high concentrations they can be better described as a paste or plastic with yield stress the best descriptor. In a small region of the transition from liquid to solid the pulp displays a rapid increase in yield stress. At high levels of separation of the pulp the increase in yield stress may reach the limit of pumpability, which in practice limits the degree of separation achievable. 


\subsection{Filtration}

Filtration is a process where a slurry or solid-liquid mixture is forced against a media with the solids retained on the media and the liquid phase passing through. As with sedimentation the degree of separation achievable with filtration is affected by the particle size, shape, surface chemistry and solids density. In tailings applications the solids are the mine tailings whilst the filtrate can contain valuable metals or be simply recycled as process water.

The product or concentrate is generally the smaller stream where water removal is targeted to transportable limits and reducing transport costs. The transportable moisture limit (TML) is a requirement for the product to be saleable and filtration technologies are selected based on their ability to reliably achieve this limit. Because the product moisture is defined by these limits, water losses through product streams are generally insignificant.

Tailings dewatering, in contrast to concentrates, is generally a much larger tonnage, processing rates and the water removal objectives are targeted to maximise water recovery or disposal constraints. While water recovery may be important (in some cases water availability can limit production) generally the selection of filtration for tailings dewatering is based on the decision to apply dry stacking of the tailings and geotechnical consideration (impoundment construction costs) have more weight than water recovery.

\subsubsection{Vacuum filtration}

Vacuum filtration in mining applications is generally seen in the form of Rotary vacuum disc filters or horizontal vacuum belt filters. In both cases vacuum is applied as the driving force to a moving filter media that first forms a cake then dries that cake. The moving filter media means that the filter behaves as a continuous processing unit operation.

The two major cake characteristics in filtration are the void fraction, which determines the saturated moisture and the pore size, which limits the degree of moisture removal and defines the resistance to flow of water passing through the cake. Both of these characteristics are affected by the size, shape and density of the particles in the slurry.

The driving force in vacuum filtration is atmospheric pressure and while liquid flow is co-current rather than counter current in sedimentation. The lack of mechanical compression means that the degree of separation possible without gas displacement is similar in both technologies. This maximum settled limit is similar to the shrinking limit observed in impoundment management. The limit depends upon the nature of particle stacking in the cake and the type of solids but the typical values for a ground mineral are in the range of 50 to $60 \%$ void volume.

Vacuum filtration has the advantage of solids handling capability whereas sedimentation would have long passed the pumpable limit that would enable solids removal from the sedimentation equipment.

For vacuum filtration to improve water recovery beyond the limits of sedimentation gas must flow into the void of the cake displacing water that can be recovered as filtrate. The nature of the void space in a cake can be best described as pores or channels passing between the solid particles.

When the tailings have a low portion of sub $20 \mu \mathrm{m}$ material, low cake moistures can be achieved and filtration capacities in the range of 1,000 to $5,000 \mathrm{~kg} / \mathrm{m}^{2} \mathrm{~h}$ are achievable.

When tailings contain a significant amount of fine material, the capacity decreases rapidly and capacities can drop to below $100 \mathrm{~kg} / \mathrm{m}^{2} \mathrm{~h}$.

\subsubsection{Pressure filtration}

Similar variables exist in pressure filtration however the use of pressure as a driving force means that the filters are operated as batch operating unit operations. Various forms of pressure filters are utilised in mining operation and in cake filtration the most common forms are the vertical plate pressure filters with either recessed chamber plates or membrane plates. Tower filters are also utilised for in mining 
applications, mostly for mineral concentrates or applications where dry cake or good cake washing are required.

The driving force for pressure filtration is significantly higher and employment of mechanical compression means that a higher degree of water removal can be achieved. Here the void fraction is reduced and the typical range is from 45 to $55 \%$ void volume. In cases of ultra fine particles and high clay contents this can decrease to $35 \%$ void volume.

Pressure filtration with the limitation of fixed volume chambers and technical time associated with batch filtration does not achieve the very high capacities that are possible with vacuum filters. Using conventional fast opening double sided membrane filter presses can achieve capacities of between 400 and $600 \mathrm{~kg} / \mathrm{m}^{2} \mathrm{~h}$ with easily dewatered material.

Where there is a large portion of clays or the particle size is small the filterability decreases and achievable moisture increases. Under these conditions the filtration rate may fall to below $100 \mathrm{~kg} / \mathrm{m}^{2} \mathrm{~h}$.

\subsection{Deposition strategies}

Tailings storage schemes can be categorised into three different strategies, as shown in Figure 1. Conventional or thickened tailings, where the tailings are transported to a dam for disposal, water recovery can be either from the process or the dam (or both). Paste disposal where a highly thickened paste is transported for either underground disposal or surface deposition, with limited water recovery after the paste is produced. Finally dry stack tailings where filtered tailings are transported to a disposal site and compacted with no water recovery achieved at the final deposition point.
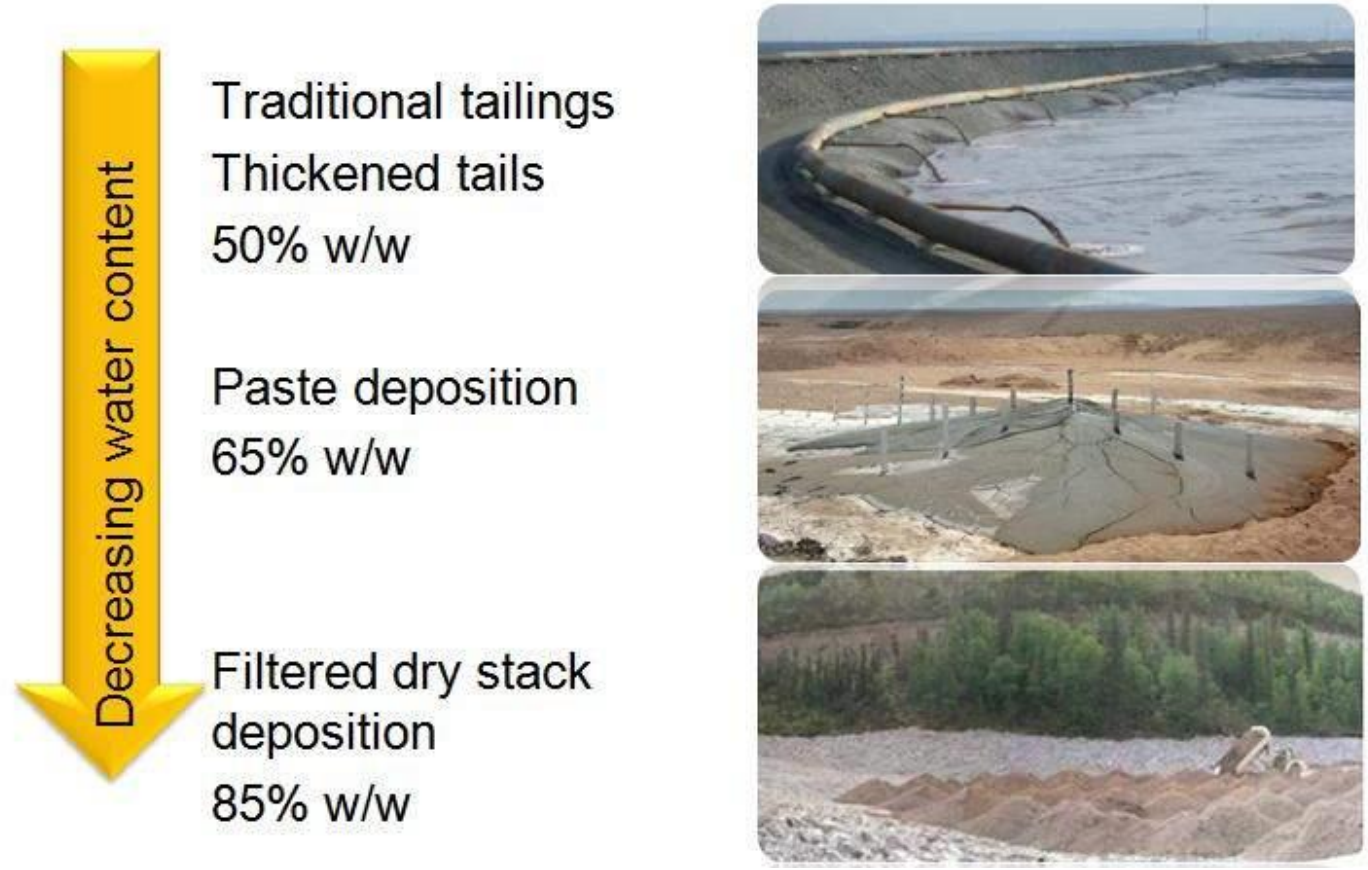

Figure 1 Deposition strategies

\subsection{Conventional tailings}

Thickening increases water recovery and since the development of high rate thickeners in the 1980s this disposal strategy is the one used predominantly in mining operations. Water consumption for mineral processing operations can vary from 0.4 to $1 \mathrm{~m}^{3} / \mathrm{t}$ of solids processed. Water is recovered either at the processing plant in a thickener or from the dam. Water losses are largely defined by the prevailing atmospheric conditions at the tailings dam. 
Settling in the dam will trap water within the settled solids and water will be lost from the dam in the form of evaporation or seepage. Efficiency is generally higher where water is recovered in the thickener at the processing facility due to lower pumping costs and shorter contact times between the process water and waste material. The operation of the thickener must accommodate fluctuations in the process stream to deliver a clear overflow and thickened underflow. This control is achieved by manipulating both the flocculant addition and the rate of underflow pumping. The flocculant addition should be adjusted to suit the solids input and is mostly affected by the processing rate, so a gram per ton ratio control is commonly used. The discharge rate of underflow slurry is manipulated to maintain a steady solids inventory in the thickener. This solids inventory will determine the achieved underflow slurry rheology and water recovery to overflow. Nevertheless many installations operate with water recovery below design limits largely through conservative control and low prioritisation of thickener optimisation.

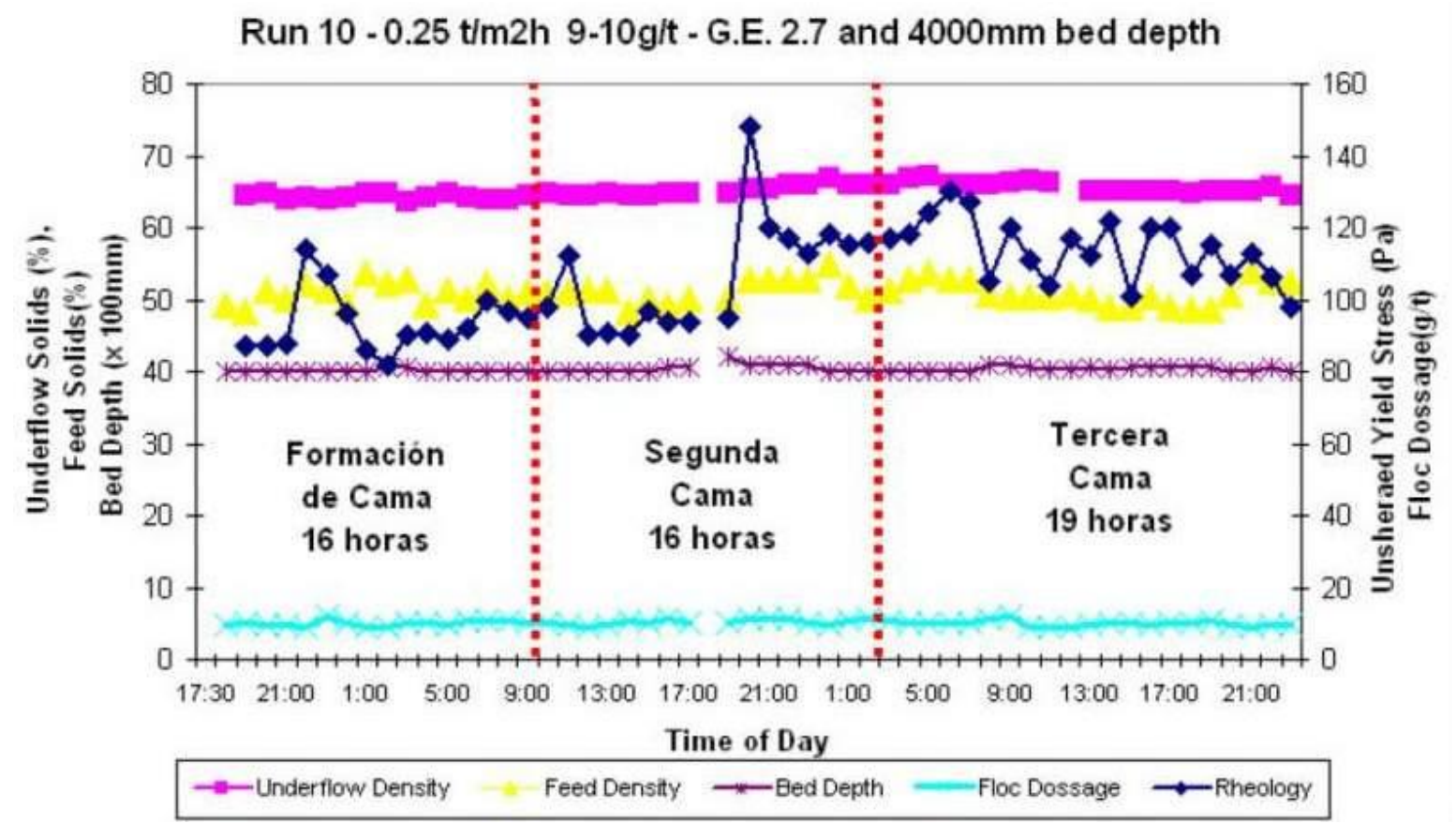

Figure 2 Thickener underflow yield stress

Operating thickeners with constant underflow density does not guarantee consistent rheology, as shown in Figure 2 where the yield stress is variable under constant density operation. Both ore variability and flocculant addition can have significant effects on thickener performance and on the unsheared yield stress. As shown in Figure 2, despite underflow density and flocculant dosage being relatively constant the yield stress varies considerably during pilot thickener trials. Yield stress is a good indicator of the slurry rheology and control strategies that have a feedback to Yield stress may produce better control than traditional control systems when operating close to the slurry flow limits.

Most tailings storage facilities require frequent changes to the final discharge point. Combined with changes to the underflow yield stress, this variability can result in significant variations in pumping system performance. Pumping systems designed to operate near a maximum yield stress can under perform as operators adopt lower density setpoints to avoid blockages or unexpected shutdowns. Lower underflow densities result in lower water recovery and reduced tailings dam lifetime or increased costs.

Yield stress can be measured automatically using rheology batching systems, such as are often employed in product pumping systems however they are seldom adopted in tailings transport systems. To a large extent this can be explained because underflow density is more easily measured and as a consequence most control systems are designed to control underflow density.

Good control systems should be able to monitor the rate limiting variable and apply control strategies to maintain optimum conditions. Often this rate limiting step is defined by pumping capacity. Simple density 
control strategies (Figure 4) do not control thickener inventory or flocculation and may lead to cyclic loading and emptying with the consequent underflow variability. Better strategies (Figure 5) keep the thickener inventory constant through feedback from either bed level or pressure, and utilise flow control to ensure that pipeline disturbances are never seen by the thickener. By controlling flocculation and solids inventory, the thickening process is stabilised and consistent, optimum; underflow density can be achieved through manual optimisation. More advanced systems can use measurements of the solids feed rate to improve the control system dynamics.

Thickener inventory is more complex than a simple bed level measurement that considers a cylindrical model and is applicable in a narrow operating range with high bed levels as indicated in Figure 3 . Thickener inventory is a function of the bedmass, bedheight and thickener dimensions.

The thickener inventory can be measured by the interface height and pressure.

$$
\begin{gathered}
B=g \int_{h=0}^{h=H} \text { density dh } \\
B=g\left(\frac{a h^{2}}{2}+b h\right)^{H} \\
a=\frac{-2 B}{H^{2}} \\
b=-a H \\
\text { Inventory }=\int_{0}^{h_{c}} \pi h^{2} \theta^{2} x(a h+b) d h+\int_{h_{c}}^{H} \pi R^{2} \times(a h+b) d h
\end{gathered}
$$

Where:
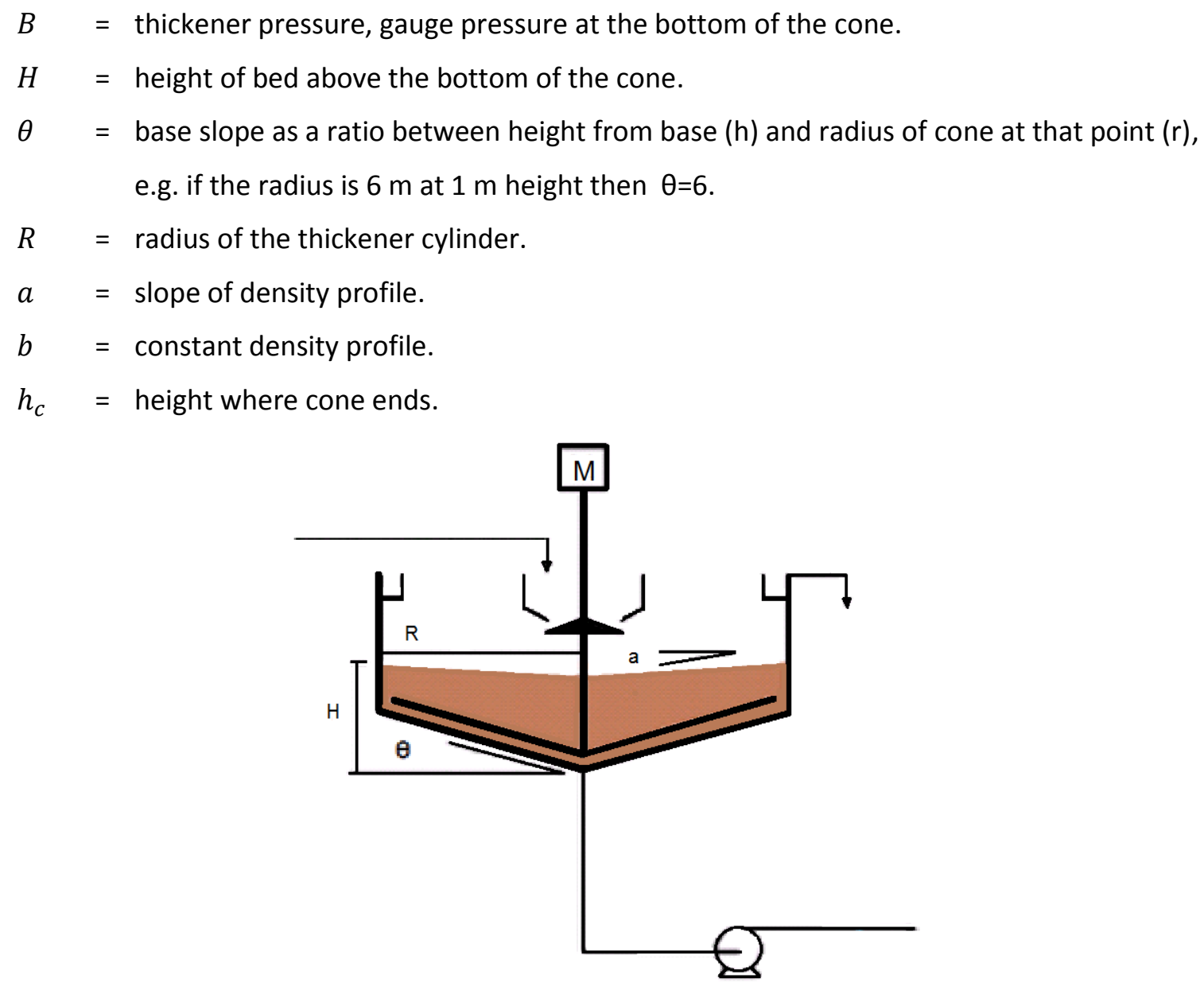

Figure 3 Thickener geometry 
Maintaining constant bed inventory can be effected by changes in the density profile. Most systems measure bed level at a single point assuming the bed surface to be level and constant. When the thickener operates with the bed level in the thickener cone or where the surface of the bed is not level then more than one point of bed level is required to measure the slope of the density profile (a) and hence the thickener inventory.

Feedwells have a significant influence on thickener performance as does the flocculant dosing control. Flocculation is controlled by varying the flocculant pump speed to achieve a consistent flocculant dosage rate per tonne of dry solids feed. Bed level can be used as feedback to control the dosage ( $\mathrm{g} /$ tonne) set point, either manually or through a master PID loop with an output cascaded to the dose-rate (ratio) controller.

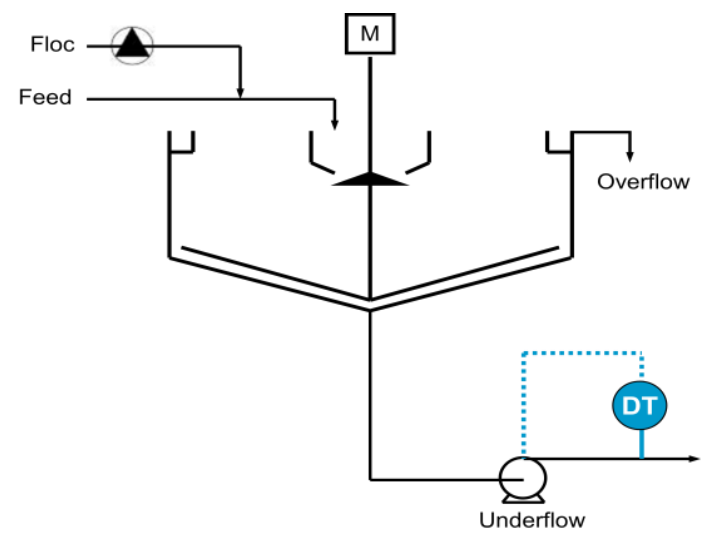

Figure 4 Basic control

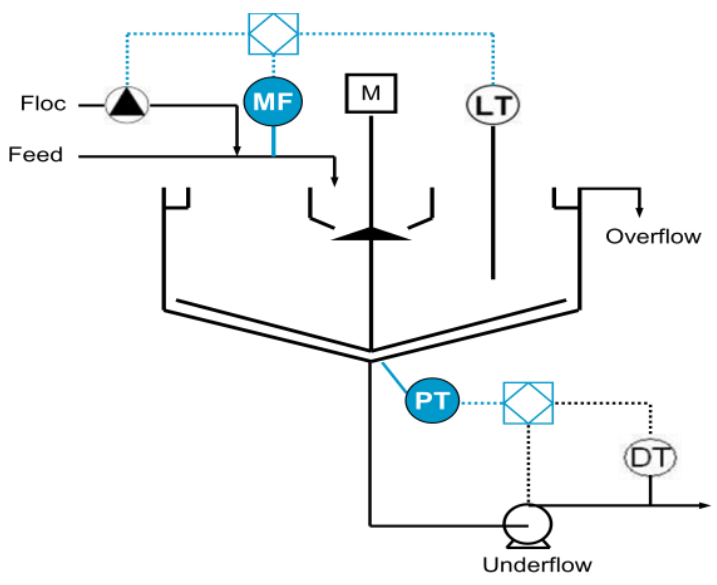

Figure 5 Flow control

Water quality is also affected by the water recovery strategy (Figure 6). Water recovered from a thickener is in contact with the solids for a relatively short time and is not adversely affected by evaporation that can concentrate dissolved solids. Water recovery from a tailings dam is subject to more complex conditions. Evaporation concentrates metal salts and changes in the water chemistry can occur either through precipitation or dissolution of minerals. These changes in water chemistry can have undesirable effects on the concentrator's performance. 


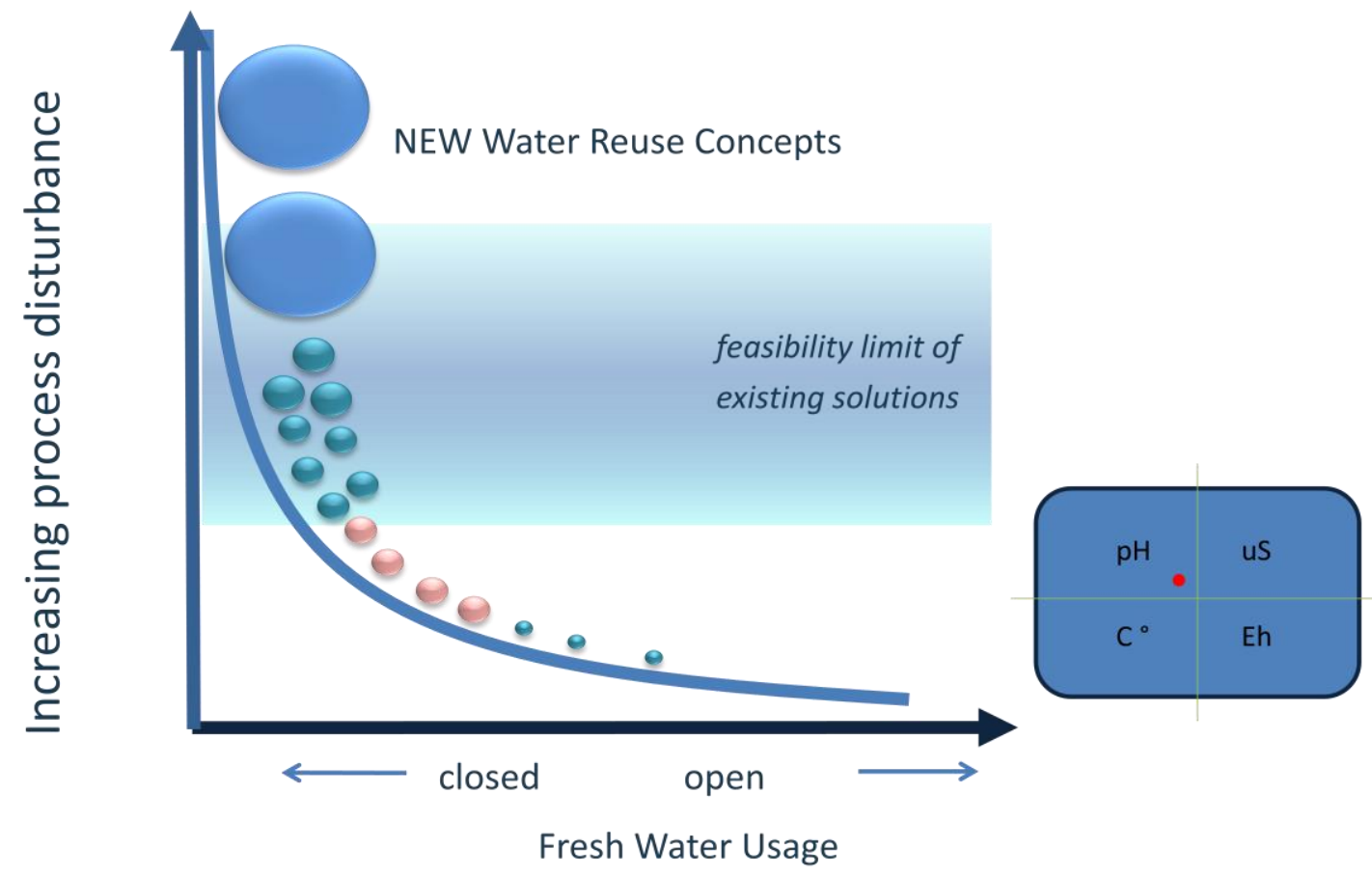

Figure 6 The effects of solute concentration versus Process water recycle rate

\subsubsection{Paste disposal}

The operation of paste plants can be even more susceptible to upsets than thickened tailings and the high inventory required in paste thickeners to ensure sufficient bed dewatering leads to dynamics that extend beyond the shift schedule. Both of these factors make automation important. The design of surface paste disposal sites is based on the beach angle achieved. Whilst the beach angle is largely a function of underflow density, for any given underflow density the way the slurry is handled can influence the yield stress as applying shear in the pumping system breaks flocculants and rearranges the particle packing. This shear thinning may help to assist pumping at the risk of reducing the deposition angle in the disposal site. A typical yield stress vs. shear is shown in Figure 7, from a laboratory scale experiment.

High yield stress paste surface disposal systems (utilising positive displacement pumps) are in operation however recently more interest is being shown in systems that limit the sheared yield stress to approximately $200 \mathrm{~Pa}$ to simplify centrifugal pumping systems. Often low solids paste systems fail to achieve high beach angles but are attractive because of the simplified pumping systems and the resulting delay of capital investment, due to higher impoundment cost from the low beaching angles.

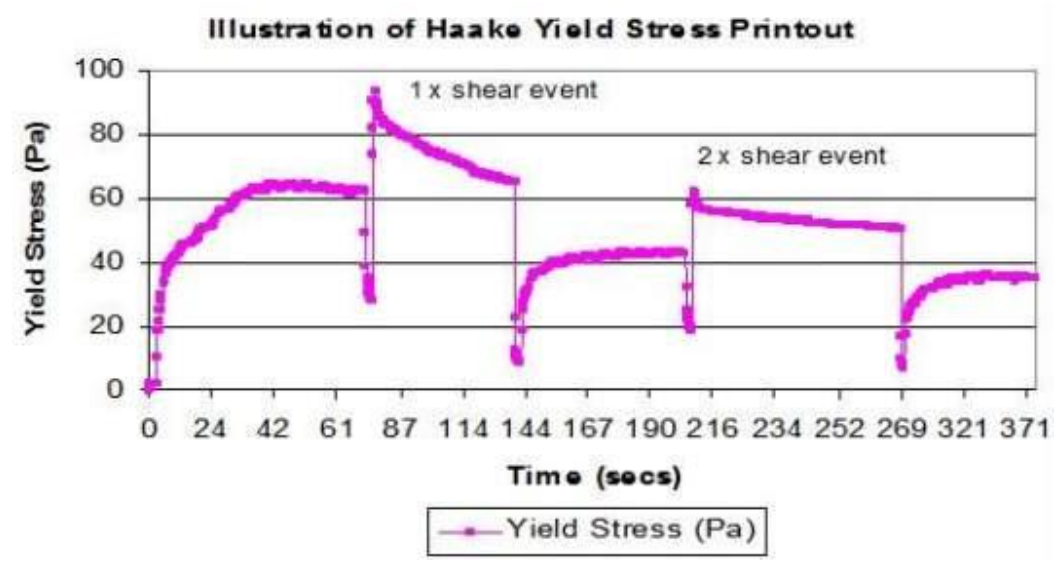

Figure 7 Yield stress versus shear 
A more extreme example of paste is applied in the backfill systems where thickened tailings are mixed with a binder such as cement for disposal underground. The strength of the backfill is influenced by the amount of binder, initial moisture content, and the surface area of particles in the paste. Achieving a high cured backfill strength is the objective of backfill operations, this balanced by operability considerations and the operating cost (which is largely dependent upon the cement addition).

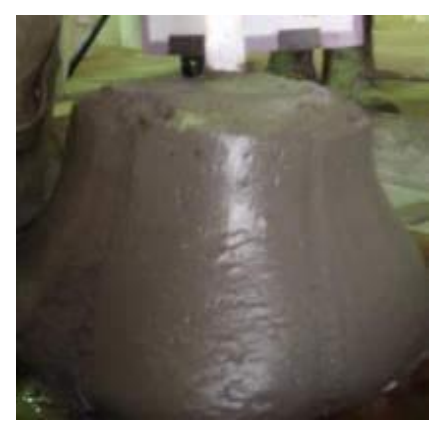

(a)

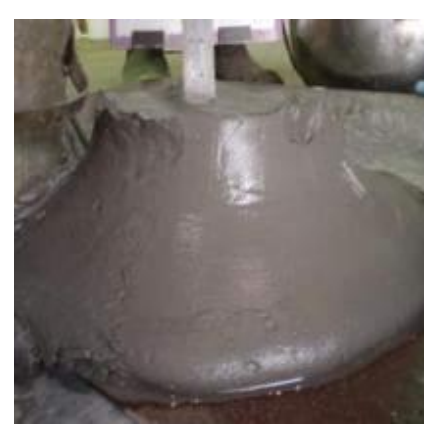

(b)

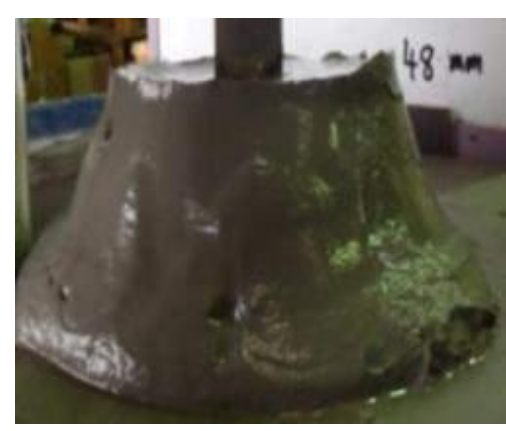

(c)

Figure 8 Slump tests on paste after high shear mixing and cement addition; (a) $76 \%$ w/w; (b) $75.5 \% \mathrm{w} / \mathrm{w}$; (c) $75 \% \mathrm{w} / \mathrm{w}$

The amount of cement is minimised by mixing a paste with a minimum amount of water. In many cases a suitable paste density cannot be achieved in thickeners alone and the thickened tailings are mixed with filtered tailings and cement to achieve an optimum mixture. These hybrid systems that utilise both filtration and thickening can provide excellent management of paste rheology as the two streams are mixed in high shear mixing systems. Figure 8 shows the relative yield stress of the thickener $\mathrm{u} / \mathrm{f}$ and the reconstituted paste. Operating the thickener with moderate underflow densities ( $\sim 100$ Pa yield stress) enables easier control of the underflow and lower thickener unit costs (in both capital and operating). Above $75 \%$ solids there is a rapid increase in yield stress, increasing the underflow density results can create difficult conditions for control. High shear in the cake-slurry mixing stabilises the yield stress of the paste which is optimised for underground placement and strength. Thickened underflow not required for backfill can be sent to a surface storage facility.

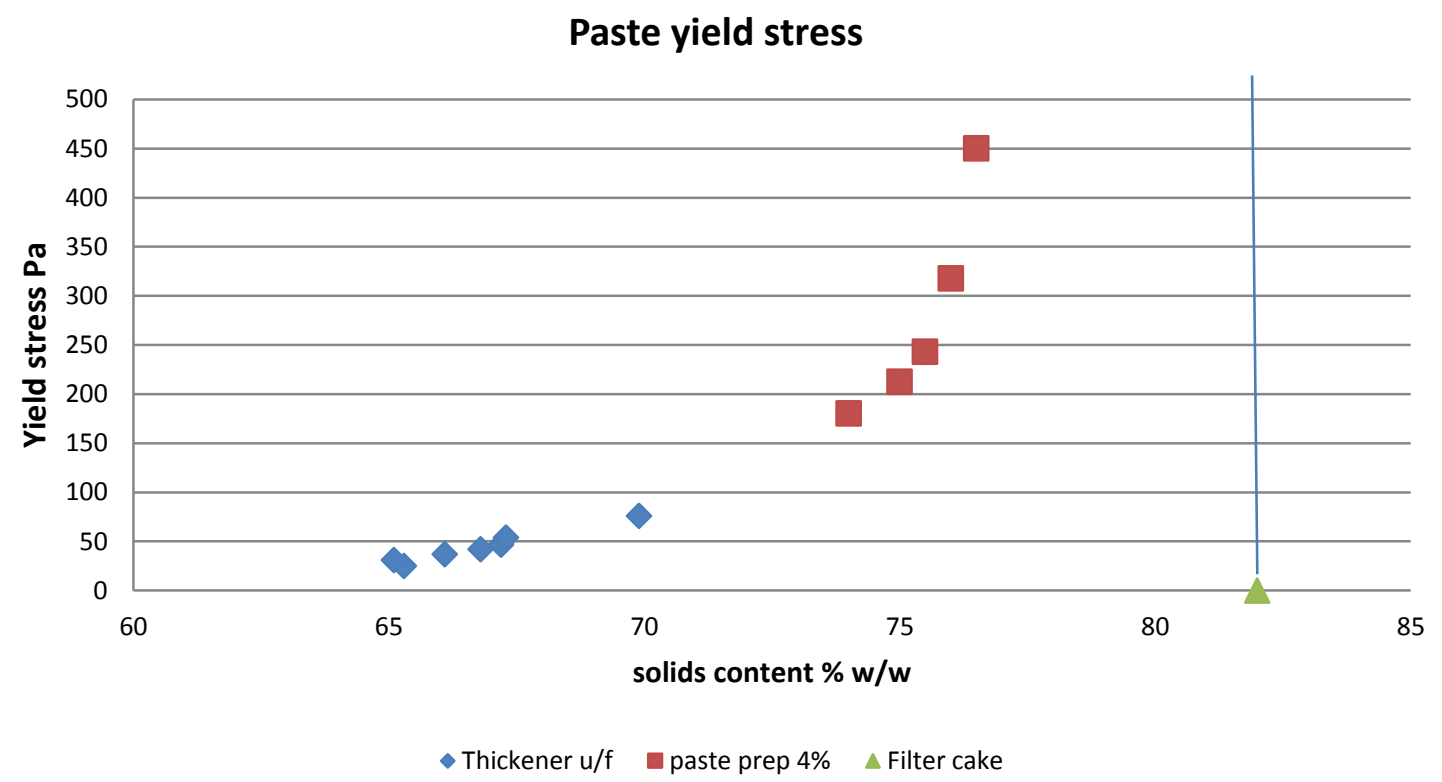

Figure 9 Yield stress versus solids concentration 


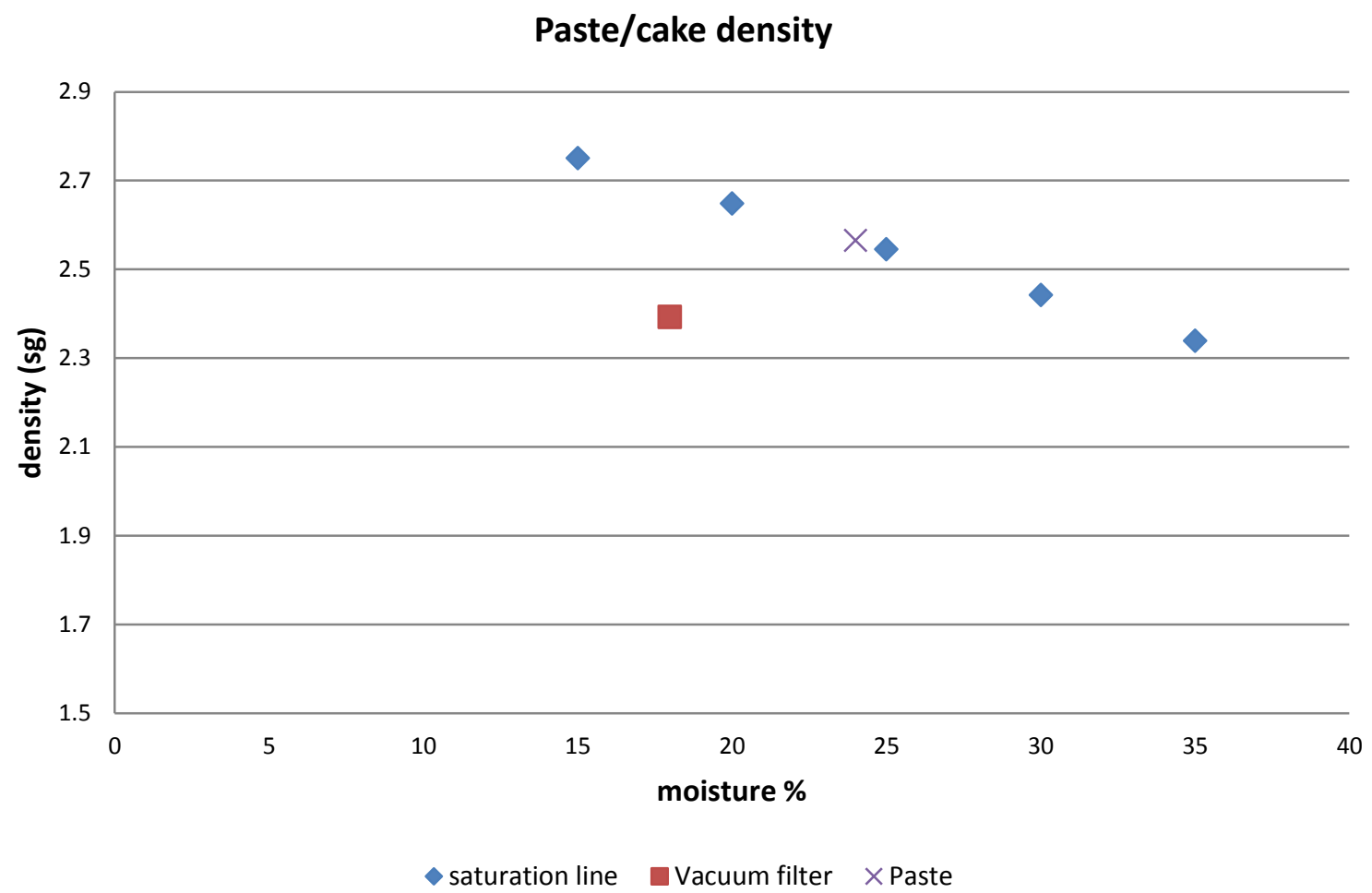

\section{Figure 10 Dry stack density results}

With the decision to blend both filter cake and thickened underflow comes the flexibility to operate the thickener in a more stable mode. For a case where the optimum paste contains 75 to $76 \%$ solids after cement addition, filter cake with $80 \%$ solids is mixed with thickener underflow of $65 \%$ solids. By reducing the thickener underflow density a lower torque and hence cost thickener can be selected and by filtering only a portion of the tails stream a smaller filter can be selected.

By optimising the mass split and degree of separation in each stage significant savings in capital cost can be realised.

The filtration stage produces a solid that has differing properties depending upon the separation forces and degree of separation. To achieve a high degree of separation, pressure filtration creates a densely packed cake. With this tight packing only minimal air is introduced into the cake to achieve our required $80 \%$ solids. In contrast vacuum filtration produces a much lower density of cake that requires air to dry the cake below the saturation line.

In a mechanism similar to shear thinning, vibration or shear stress of the vacuum filter cake causes a rearrangement of fine particles in the cake increasing the cake density up to that required for the paste preparation. In comparison to pressure filter cakes this lower cake density assists the repulping with thickened slurry required for the paste preparation. However the greater air displacement requires a significant energy input. 
Cake Moisture vs. Drying Time

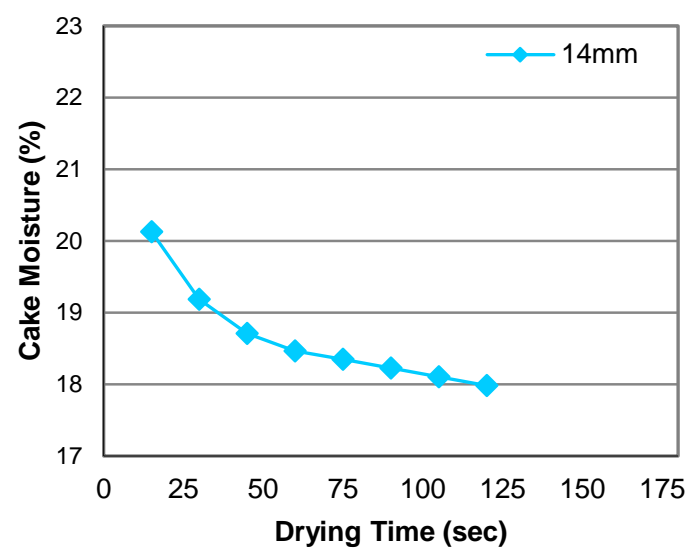

Figure 10 Cake drying

Cake moisture vs. Filtration rate

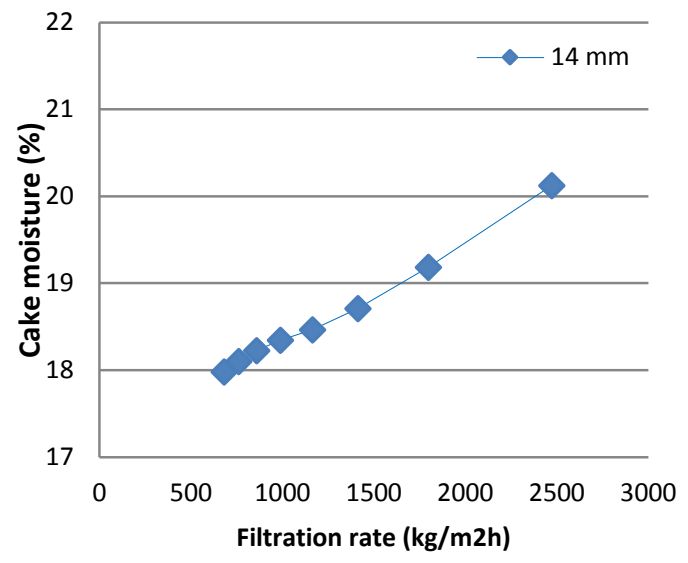

Figure 11 Filtration rate

With minimal cake drying high capacities are achieved, however cake properties are still fluid and materials handling can be difficult. By adjusting the drying time or vacuum level the cake moisture can be adjusted to suit the paste mixing system. Flocculant assists the cake formation rate and changes the cake properties (Figure 12), the flocculant holds the particles together which helps to resist movement of the particles or flow, making the cake less fluid.

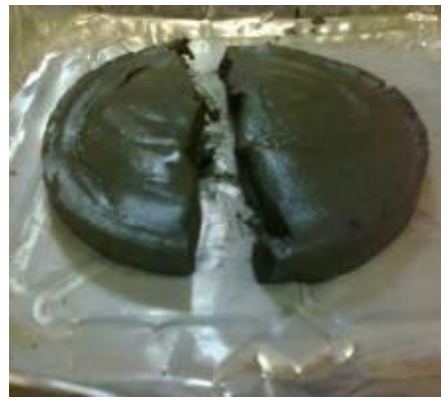

(a)

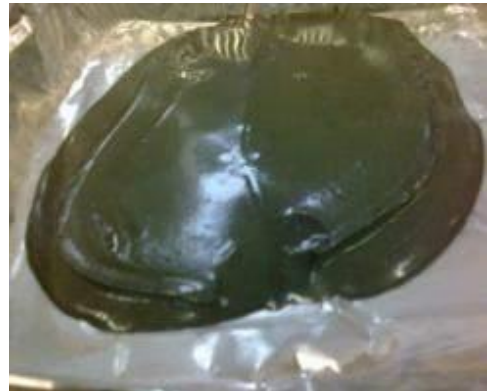

(b)

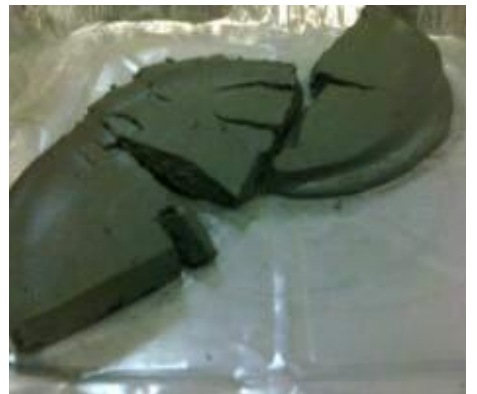

(c)

Figure 12 Photos of filter cake properties; (a) filter cake $78 \% \mathrm{w} / \mathrm{w}$; (b) $78 \%$ plus vibration; (c) $77.5 \%+54 \mathrm{~g} / \mathrm{t}$ flocculant 


\subsection{Dry stacking tailings}

When dry stacking is selected as a strategy for tailings disposal, filtration of tailings should be selected. The moisture required is defined by the geotechnical properties where the compacted strength is defined to suit the required stack design. Over-drying recovers more water with the consequence of a weaker compacted strength and water will have to be added in the compaction process, negating the savings achieved in filtration.

For dry stacking tailings deposition the target moisture content is defined by the geotechnical requirements considering the seismic activity and geographic location. The stacking strength will be a function of compaction (or compacted density) and the moisture of the filtered tailings. These properties can be measured using the Standard Proctor testing as described by ASTM D698 (ASTM International 2011) (Figure 13). This optimum moisture content can be determined for a given level of compaction that will achieve the bulk solids properties that are required to form a stable deposit. At the required stacking moisture the solids have passed the paste flow ability point but still have enough moisture to hold the particles together. At this point the compacted solids have the highest strength, which allows vertical stacking with a high angle of repose and forms a permanent structure. This compacted solid still contains significant amounts of water that may drain or evaporate from the dump and reasonably high water content is required to increase the compacted strength.

The optimum moisture content is slightly below the saturated cake moisture content or zero air voids line indicating the need for gas displacement during filtration to achieve the required moisture content. Typically a moisture content of 15 to $18 \%$ moisture is required for tailings with a solids specific gravity of 2.6. Where clays are present a higher compaction level may be required to achieve the necessary strength.

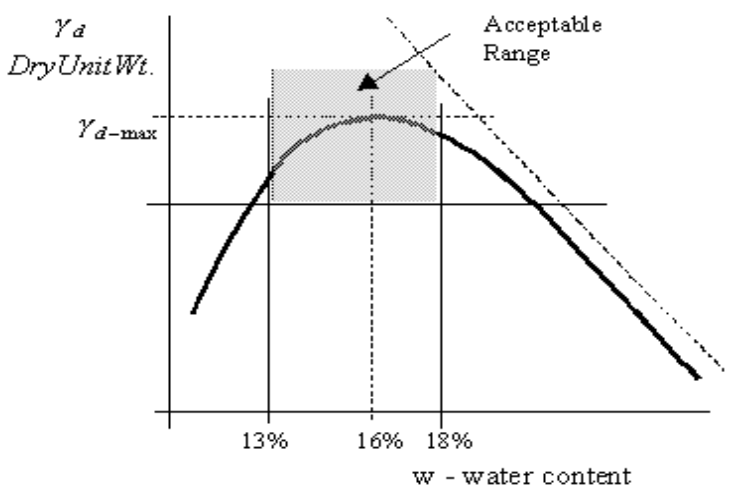

\section{Figure 13 Compaction testing}

Pressure filtration can easily achieve the required moisture content and when high tonnages are required they are available in very large sizes. As shown in Figure 14 very low moisture contents are possible although unnecessary.

Testing can determine the technology and economic evaluation will determine the best choice for each application.

As shown in Figure 14 both chamber filtration and membrane filtration can achieve the required moisture. The results for chamber filters (orange markers) are a little erratic indicating cake cracking and air bypassing the filter cake. For the membrane filters (blue markers) tests the higher consolidation pressure prevented cake cracking and the drying was more stable, the required moisture was achieved with minimal drying. 
Tailings filtration

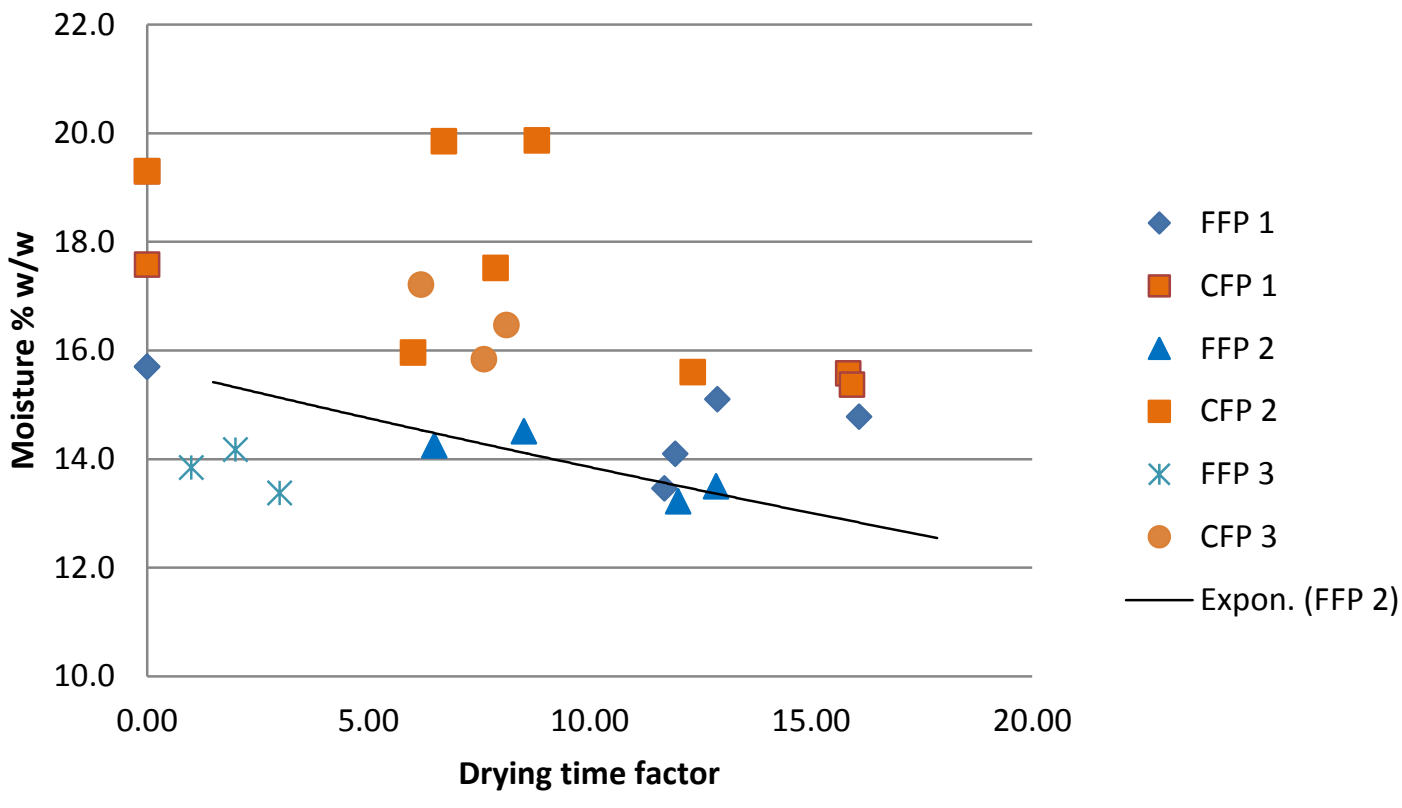

Figure 14 Pressure filtration test results

\section{Conclusions}

When considering large tailings filtration plants, the energy required to recover the water from the tailings is an important factor. The energy required for lighting, materials handling and general equipment is somewhat independent of the type of dewatering technology. The variable power can be considered to be slurry pumping, pressing and blowing air or vacuum pumps required for filtration.

Vacuum filters use low pressure slurry pumping and the dewatering is achieved via vacuum pumps. In the cake forming section the vacuum consumption is low and in the drying section the vacuum consumption is high and increases as the cake is dewatered. Where long drying times are required large amounts of energy are required.

Pressure filters use higher pressure Slurry pumping, for less than $25 \%$ of the cycle. The energy required for cake compression is similar but slightly higher than slurry pumping and then compressed air used for dewatering is the major energy input.

The best solutions are the ones that can achieve the required moisture with the minimum of drying time. Drying can consume significantly more energy than pumping and cake compression.

More important than any of the process performances, is, safety, the system reliability, operability and maintainability.

\section{Bibliography}

ASTM International 2011, ASTM D698, ASTM International, West Conshohocken.

Bloss, ML \& Rankine, R 2005, 'Paste fill operations and research at Cannington Mine', Proceedings of the Ninth Underground Operators' Conference, The Australasian Institute of Mining and Metallurgy, Melbourne, pp. 141-150.

Davies, M 2010, 'Dewatered tailings practice - trends and observations', in HW Sorstokke \& RL Soderberg (eds), Proceedings of the 14th International Conference on Tailings and Mine Waste, Taylor \& Francis Group, London.

Jewell, RJ \& Fourie, AB (eds) 2006, Paste and Thickened Tailings - A Guide, 2nd edn, Australian Centre for Geomechanics, Perth.

Liu, L n.d., CE 240 Soil Mechanics \& Foundations Lecture 3.3: Soil Compaction, University of Connecticut, Mansfield, viewed 17 March 2015, www.engr.uconn.edu/ Ianbo/CE240LectW033Compaction.pdf

Palmer, J \& Viswanathan, V 2012, 'Optimising unit operations in paste dewatering', Proceedings of the 14th International Seminar on Paste and Thickened Tailings, RJ Jewell \& AB Fourie (eds), Australian Centre for Geomechanics, Perth, pp. 57-66. 
Rogers, JD n.d., Mechanical Compaction of Soils for Engineering Purposes, Missouri University of Science and Technology, Rolla, viewed 17 March 2015, web.mst.edu/ rogersda/umrcourses/ge441/online_lectures/compaction/

Rogers, JD n.d., Drainage and Erosion Control, Missouri University of Science and Technology, Rolla, viewed 17 March 2015, web.mst.edu/ rogersda/umrcourses/ge441/online_lectures/drainage\&erosion_control/

Rogers, JD n.d., Slope Face Treatment, Missouri University of Science and Technology, Rolla, viewed 17 March 2015 , web.mst.edu/ rogersda/umrcourses/ge441/online_lectures/slope_face_treatment/

Shah, DL \& Shroff, AV 2003, Soil Mechanics and Geotechnical Engineering, A.A. Balkema, Rotterdam.

Skeeles, BEJ 1998, 'Design of paste backfill plant and distribution system for the Cannington Project', in ML Bloss (ed.), Proceedings of the Sixth International Symposium on Mining with Backfill, Australasian Institute of Mining and Metallurgy, Melbourne, pp. 59-63.

Venkatramaiah, C 2006, Geotechnical Engineering, New Age International, New Delhi.

Wakeman, RJ \& Tarleton, ES 1999, Filtration Equipment Selection Modelling and Process Simulation, Elsevier Science Ltd, Oxford. 
